\title{
Tipos de familia
}

Types of Family

Jorge Pacheco Tejada

Universidad Católica San Pablo, Perú

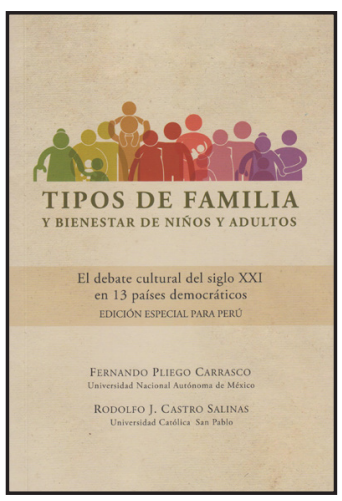

Pliego, Fernando \& Castro, Rodolfo (2015).

Tipos de familia y bienestar de niños y adultos.

El debate cultural del siglo XXI en 13 países democráticos.

Universidad Católica San Pablo

Instituto para el Matrimonio y la Familia

Arequipa, Perú, pp. 129.

ISBN 978-9972-825-84-2

La reflexión sobre los Tipos de familia es un tema que cautiva el interés, sobre todo en la coyuntura en la que la Iglesia ha abierto el debate y reflexión en torno a la familia. Es un libro en lenguaje sencillo con cifras contundentes y análisis claros que se desprenden de la información recogida que fácilmente suscita el interés y motiva a la valoración de la familia como institución de la que depende el futuro de la sociedad.

El libro Tipos de Familia y bienestar de niños y adultos, de Fernando Pliego Carrasco y Rodolfo Castro Salinas, recoge una vasta variedad de resultados de investigaciones y aborda el tema de la familia desde la perspectiva social, política, económica, psicológica, sociológica, religiosa y eclesial. Los textos de consulta, pero sobre todo las fuentes de datos, permiten abordar los diversos aspectos de manera clara y fundamentada.

Desde el prólogo se plantea el tema, de manera motivadora, a partir de dos preguntas: «¿Habrá una estructura familiar que correlacione positiva y significativamente con mejores niveles en la calidad de vida de las personas? ¿Cuál es la situación de la familia en el Perú?» 
La investigación se fundamenta en la información proporcionada por 351 publicaciones académicas y oficiales desde 1995 en 13 países democráticos. En la Introducción se establece que para evitar los prejuicios personales o ideológicos que surjan de abordar este tema tan cercano a la vida personal y lograr una información objetiva y representativa, los autores han seguido una metodología que incluye: recuperar, analizar y sintetizar trabajos únicamente basados en encuestas representativas o en información censal.

El libro está integrado por cinco secciones. La primera es un llamado a leer el libro con dos actitudes fundamentales: solidaridad y autocrítica para lograr objetividad y responsabilidad social. Solidaridad que debe llevarnos a apoyar y/o promover programas públicos o privados que atiendan las necesidades de familias en condiciones de vulnerabilidad. Solidaridad no sólo de tipo asistencial, sino preventiva. La responsabilidad social se inicia con una posición autocrítica para animar a nuestros hijos a construir mejores familias que las que les heredamos, donde haya espacios más sanos de cooperación y justicia. Es esta una solidaridad comprometida con el desarrollo social en la medida que cambien las causas que originan la vulnerabilidad de tantas familias.

En la primera sección se ve que, a partir de la encuesta mundial de valores aplicada a 59 países, los autores concluyen que la familia es el tema cultural más relevante en las sociedades contemporáneas y no solo en sistemas democráticos, sino en sistemas autoritarios, en sociedades de alto, medio y bajo nivel de crecimiento y en países de culturas diversas, latinas, anglosajonas, orientales o africanas.

El texto deja sentado que una de las tendencias más importantes es que hay cada vez mayor pluralidad en los tipos de familias. Anteriormente, el patrón cultural predominante eran parejas casadas en primeras nupcias. En la actualidad se observa: parejas convivientes, divorcios, separación, casados en más de dos ocasiones, hijos provenientes de matrimonios o convivencias previas, parejas sin hijos y que no desean tenerlos, etc. Un dato relevante es que en el Perú, en apenas 17 años, el porcentaje de población casada de 15 a 49 años de edad disminuye de $34.3 \%$ a $22.4 \%$ y el porcentaje de convivientes se eleva de $24 \%$ a $34.2 \%$. Esta realidad ha hecho que ya no se pueda hablar de «familia», sino de «tipos de familia».

En la siguiente sección, titulada «Consecuencias de los diferentes tipos de familias en el bienestar de niños y adultos», los autores se preguntan: ¿El surgimiento de diversos tipos de familia trae consecuencias en el bienestar de los niños y los adultos? ¿Es causa de que se desarrollen carencias y problemas de bienestar en la población? En la primera parte de esta sección se exponen ejemplos de investigaciones en torno a cinco problemas sociales muy importantes: violencia de pareja, abuso sexual y físico contra niños, delincuencia juvenil, deserción escolar y consumo de drogas. En la segunda parte se analiza la información recibida. Los resultados de las investigaciones son contundentes y alarmantes: 
- La frecuencia de problemas graves respecto a violencia e inseguridad aumentan de manera significativa en la población que vive en unión libre.

- El riesgo de haber sufrido abuso sexual es 5.2 veces mayor en los menores que no vivían con ambos padres.

- La deserción escolar en adolescentes que cursan la secundaria es significativamente mayor entre adolescentes que viven con mamá separada o divorciada.

En la sección «Vínculo de pareja entre hombre y mujer es lo determinante», los autores abordan el tema respecto a las parejas del mismo sexo. Se preguntan: ¿Cuáles son las consecuencias que lleva consigo en el bienestar de adultos y, sobre todo, en los niños? Lo primero que establecen es que hay pocos estudios al respecto, no obstante con la poca información, llegan a tres conclusiones de manera fundamentada:

- En las democracias, el tipo de pareja que determina el bienestar o los problemas de bienestar de la población es el formado por hombre y mujer.

- No se dispone de información sistemática que permita fundamentar la opinión según la cual las parejas del mismo sexo podrían sustituir la necesidad de los niños de contar con el cuidado de una pareja conformada por un hombre y una mujer.

- Las parejas del mismo sexo sólo conforman alrededor del $1 \%$ de la muestra trabajada, por lo tanto no se considera un dato determinante ni influyente en las tendencias de bienestar en los países democráticos.

Finalmente, con el ánimo de contribuir a la discusión, los autores se plantean dos preguntas en esta parte conclusiva del libro: ¿Por qué las personas casadas tienen, en promedio y en términos generales, un bienestar mayor que los adultos con otro estado civil (cohabitantes en unión libre, divorciados, separados, viudos o solteros)? y ¿Por qué los niños que viven con sus dos padres biológicos también tienen un bienestar significativamente mayor que los niños en otras situaciones familiares?

Entre los muchos factores, destaca uno muy importante: la solidaridad de vida. Cuando los niños viven con los padres biológicos, en este tipo de familia se desarrolla con más facilidad el vínculo de solidaridad donde las personas comprometen recursos fundamentales de su propia vida y no un simple apoyo circunstancial.

Se reconocen también otros factores que garantizan el bienestar, tales como el entorno económico, social y político, que permiten existencia de mercados laborales competitivos que ofrecen trabajos estables y bien remunerados; la calidad de las instituciones 
públicas y privadas; el estado de derecho; la protección de las garantías individuales; el nivel educativo, entre muchos otros factores.

No obstante, es necesario asumir y promover una «perspectiva de familia» para orientar el enfoque de políticas públicas y privadas. Esta perspectiva familiar, proponen los autores, debe tener dos grandes estrategias: una asistencial, y otra educativa y preventiva. En la estrategia asistencial, las familias más frágiles deben contar con el apoyo decidido de los programas de ayuda provistos por organizaciones gubernamentales, privadas y de la sociedad civil. Y respecto a los programas educativos y preventivos, dicen, es la mejor manera de solidarizarse con el futuro de las nuevas generaciones.

En resumen, podemos decir que los autores hacen una exposición muy puntual del tema que no solo queda en el acopio de datos estadísticos, sino que formulan válidas conclusiones por la objetividad y precisión en el análisis.

La biblio-hemerografía que han utilizado (358 referencias) la han agrupado por países y la codifican sobre la base de 11 países y 10 indicadores de bienestar: educación, seguridad física, relaciones con los hijos, funcionamiento de la pareja, salud sexual y reproductiva, salud mental, salud física, ingresos y trabajo, vivienda y adiciones, finalmente, satisfacción de vida. Información esta que sirve para determinar niveles de bienestar de niños y adultos, y es básica para tomar decisiones en las sociedades democráticas respecto a la protección y promoción de derechos humanos básicos. Igualmente, obliga a una atención destacada de parte de los gobiernos y de sus principales instituciones privadas y sociales.

En suma, este libro, además de ser un trabajo académico que recoge valoraciones de diversas variables en el bienestar de niños y adultos a partir de los tipos de familia, es una guía para poder realizar un trabajo comprometido de campo de la familia. Se caracteriza por la concisión y precisión en la presentación de estadísticas, el análisis claro y objetivo de resultados y la propuesta directa y precisa de acciones a realizar.

Constituye una obra de lectura obligada por la información de nuestra realidad y la reflexión que genera, pero, sobre todo, por la motivación que suscita en el lector respecto a lo que debe hacerse a favor de la familia en clave de «solidaridad y perspectiva familiar». Recomendamos esta obra a los psicólogos, los trabajadores sociales, los sociólogos, los agentes pastorales, políticos y educadores, pues constituye un nuevo aporte sobre la realidad de la familia en esta nueva época. 